\title{
Psychiatric evaluation of offenders referred to the Free State Psychiatric Complex according to sections 77 and/or 78 of the Criminal Procedures Act
}

F J W Calitz, BA Hons, MA, DPhil

P H J J van Rensburg, MB ChB, MMed (Psych), PhD

C Fourie, $M B C h B$

E Liebenberg, MB ChB

$C$ van den Berg, $M B C h B$

Department of Psychiatry, University of the Free State, Bloemfontein

G Joubert, BA, MSC

Department of Biostatistics, University of the Free State, Bloemfontein

Background. The increase in crime is a problem of great concern in South Africa and complications arise when the accused is mentally ill.

Objective. Analysis of the offenders referred to the Free State Psychiatric Complex from 1995 to 2001 according to section 77 (triability) and/or section 78 (accountability) of the Criminal Procedures Act (Act 51 of 1977).

Method. The study population consisted of 514 persons awaiting trial in the Free State. They were referred to the Free State Psychiatric Complex for 30 days' observation from 1995 to 2001. A data form was created and used to transfer the relevant information from the accused's clinical files.

Data analysis. The data collected were analysed by the Department of Biostatistics at the University of the Free State.

Results. The majority of the offenders were male (94.6\%) and unmarried (66.3\%). The median age of the group was 30 years. The unemployment rate was $60 \%$. Most of the referrals (84.2\%) were in terms of sections 77 and 78 . The accused were found to have mainly average intelligence (75.3\%). The main offences were theft (27.8\%), murder (18.9\%), assault (18.1\%) and rape (16.2\%). The most common mental disorder diagnosed was schizophrenia (23.0\%), with 54.3\% having no mental disorder. Nearly half the offenders (48.6\%) were found to be triable and accountable.
Conclusion. The majority of the offenders referred for psychiatric observation were found to have no mental illness and were referred back to the courts. This results in high costs for the Department of Health. To reduce the high rate of unnecessary referrals it is recommended that courts give clear reasons for the referrals according to each section 177 and 781.

The increase in crime is a problem of great concern in South Africa and complications arise when the accused is mentally ill. Although it is widely accepted that a close relationship exists between mental illness and crime, only a few South African studies have been published on this subject.

In South Africa a defendant can be referred during a trial for 30 days of psychiatric observation to assess whether he/she has a mental illness or defect in terms of section 79(2) of the Criminal Procedures Act (Act 51 of 1977). This may result in the accused being considered unfit to stand trial (section 77), or being deemed 'incapable of appreciating the wrongfulness of his act; or of acting in accordance with the appreciation of the wrongfulness of his act' (section 78). When it appears that an accused is not triable or accountable, the accused is referred for psychiatric observation to a hospital for the mentally ill or to another institution as indicated by the court (section 79(3)). ${ }^{2}$ In the Free State offenders are referred to the Psychiatric Complex in Bloemfontein.

A study conducted in Finland ${ }^{3}$ found that men diagnosed with a mental illness had a 4 times higher risk of committing violent crimes than men without a mental disorder. For women with a serious mental illness the chances were 27 times higher. Substance abuse increases the possibility of violent crimes. In a similar study Verster and Van Rensburg ${ }^{4}$ found that $77 \%$ of offenders charged with murder had a history of substance abuse and 36\% a history of cannabis abuse.

According to Vielma et al. ${ }^{5}$ schizophrenia is the most common psychiatric condition associated with violent crimes in the UK followed by personality disorders and organic brain 
syndromes. Tiihones and Eronen ${ }^{3}$ found that men diagnosed with schizophrenia were 7 times more likely to commit murder than men without schizophrenia. For women the chances were 15 times higher. In Germany, Hansen and Schmidt found that serious misconducts like murder, violence, arson and rape were mainly committed by offenders with personality disorders (74\%). Thirty per cent of the offenders charged with arson were psychotic and $10 \%$ were mentally retarded. Offenders diagnosed with schizophrenia and other non-affective psychosis committed more violent crimes than accused with manic-depression. In England Walker and McCabe ${ }^{7}$ found that $41 \%$ of mentally ill offenders were diagnosed with schizophrenia, 35\% were mentally disabled, $12 \%$ had personality disorders and $8 \%$ affective disorders.

Table I summarises the results of similar studies ${ }^{4,8-10}$ conducted in South Africa. It is clear that only a few local studies have been published on this subjects. The percentage of offenders found to be mentally ill has ranged between $42 \%$ and $57 \%$; most were diagnosed with schizophrenia, followed by mental retardation and epilepsy.

Several studies ${ }^{4,11-15}$ have been conducted to highlight tendencies with regard to triability and accountability. The percentage of offenders found to be not triable ranged between $1.2 \%{ }^{13}$ and $77 \%{ }^{15}$ Cohrane et al..$^{12}$ found that $12 \%$ of 1710 accused were unaccountable. Verster and Van Rensburg ${ }^{4}$ found that $32.5 \%$ of the offenders charged with murder were unaccountable.

\section{Objective}

The aim of the study was to analyse offenders referred to the Free State Psychiatric Complex from 1995 to 2001 according to sections 77 and or 78 of the Criminal Procedures Act (Act 51 of 1977). The specific aims were to: (i) investigate the socio- demographic characteristics of the offenders; (ii) summarise the findings regarding accountability and triability; and (iii) identify the most common psychiatric conditions associated with crime.

\section{Methods}

\section{Study design and population}

A descriptive, retrospective study was undertaken.

The sample consisted of 514 awaiting-trial offenders from the Free State referred to the Psychiatric Complex for 30 days of psychiatric observation, according to sections 77 and/or 78 of the Criminal Procedures Act, from 1995 to 2001 . The reason for their referral was the possibility that they were not triable or accountable.

\section{Measurement}

The multi-professional team of the forensic unit at the Free State Psychiatric Complex included a psychiatrist, a registrar in psychiatry, a social worker, a clinical psychologist, a psychiatric professional nurse, an occupational therapist, a neurologist and a juror.

During the 30 days of observation the accused undergoes several assessments regarding his/her physical and mental condition. The evaluation includes several psychiatric interviews, psychological tests, physical examination, psychosocial report and evaluation of the facts of the case. On admission the accused is examined physically. Thereafter the person is evaluated at least once a week using a structured psychiatric interview. The interview centres around the clinical picture, psychosocial background, the individual's account of the crime, and his/her ability to understand court proceedings. When needed, translators are

\begin{tabular}{|c|c|c|}
\hline Source & No mental illness or defect (\%) & Mental disorders (\%) \\
\hline \multirow[t]{4}{*}{ Slabber et al. ${ }^{8}$} & 42 & Schizophrenia (21) \\
\hline & & Mental handicap (11) \\
\hline & & Epilepsy (2) \\
\hline & & Bipolar mood disorder (6) \\
\hline Gagiano et al. ${ }^{9}$ & 52 & - \\
\hline \multirow[t]{3}{*}{ Verster and Van Rensburg ${ }^{4}$} & 57 & Schizophrenia (20) \\
\hline & & Epilepsy (6.3) \\
\hline & & Personality disorder (3.9) \\
\hline \multirow[t]{3}{*}{ Pretorius et al. ${ }^{10}$} & 50.2 & Schizophrenia (20) \\
\hline & & Mental handicap (4.9) \\
\hline & & Bipolar mood disorder (mania) (3.5) \\
\hline
\end{tabular}


used. Comprehensive notes are taken most often verbally. Before the final report is written by the psychiatrist a battery of physical tests is also done. All the above-mentioned information is entered into the accused's clinical file.

At the end of the 30-day observation period and after all the data have been collected, a forensic conference is held to discuss the information in detail. A diagnosis is formulated and a decision is made regarding the triability and/or acountability of the offender. Thereafter the report for the court is compiled.

A data form was compiled and used to transfer the relevant information from the accused's clinical file.

\section{Data analysis}

The data were summarised using frequencies and percentages (categorical variables) and means or percentiles (numerical variables). Subgroups were compared with regard to categorical variables using the chi-squared or Fisher's exact test.

\section{Ethics}

The study was approved by the Ethics Committee, Faculty of Health Sciences, University of the Free State. Permission was obtained from the Chief Executive Officer of the Psychiatric Complex of the Free State.

\section{Results and discussion}

Most of the participants were male (94.6\%) and single (66.3\%). The ages ranged from 12 to 75 years, with a median age of 30 years. A possible explanation for this finding was the high unemployment rate in this group.

The majority of the offenders (75.3\%) had an average $1 Q$, and only $8.5 \%$ were found to be mentally handicapped. Verster and Van Rensburg ${ }^{4}$ found that $4.2 \%$ of the participants had an IQ of less than 70

Most of the accused had only some primary school education $(42.0 \%)$ or some secondary school education (36.0\%). Fourteen per cent had passed grade 12. Sixty per cent of the participants were unemployed, 10\% were pensioners, while the rest were from different occupations, such as teachers and police officials. The high prevalence of unemployment was expected because of the high unemployment rate in South Africa. Several of the offenders were known psychiatric patients living on disability grants provided by the government.
The largest percentages of accused were from the BloemfonteinBotchabelo area (17.0\%), followed by Kroonstad (7.0\%) and Welkom (4.6\%). Approximately 5\% (4.5\%) of the participants were referred from the Northern Cape, since the Northern Cape does not have the necessary facilities.

The offenders were mainly referred according to both sections, namely 77 and 78 of the Criminal Procedures Act (84.2\%), whereas $5.3 \%$ were referred according to section 77 only, and $10.5 \%$ according to section 78 only. This might be due to the fact that for the sake of convenience, the presiding officer prefers to refer according to both sections.

The offences for which offenders were referred were theft (27.8\%), murder (18.9\%), assault (18.1\%), rape (16.2\%) and a few cases of drunken driving, vandalism and fraud. Approximately half $(45.8 \%)$ of the offenders had previous convictions. This finding is somewhat worrying because it seems that offenders with previous convictions are more likely to become involved in crime again. Previous convictions were theft (23.3\% of all participants), assault (27.6\% of all participants) and possession of cannabis (9.5\%). A total of $9.9 \%$ had charges of murder, rape, drunken driving, vandalism and fraud.

Approximately one-fifth (20.4\%) of the offenders were reported to be under the influence of alcohol and $23.0 \%$ under the influence of cannabis at the time of the offence. Verster and Van Rensburg ${ }^{4}$ reported that $77 \%$ of the offenders charged with murder had a history of alcohol abuse and $36 \%$ of cannabis abuse. As already mentioned, a study conducted in Finland ${ }^{3}$ found that substance abuse increased the possibility of violent crime in men by $15 \%$ and in women by $55 \%$.

More than half $(54.3 \%)$ of the offenders were found to have no mental illness or defect. These findings are supported by the studies of Gagiano et al. ${ }^{9}$ (52\%), Slabber et al. ${ }^{8}$ (42\%), and Verster and Van Rensburg ${ }^{4}$ (57.9\%).

Schizophrenia was the most common mental disorder diagnosis in the study population (23.0\%). Similar findings were reported by Slabber et al. ${ }^{8}(21 \%)$, Verster and Van Rensburg ${ }^{4}(20 \%)$ and Pretorius et al. ${ }^{10}$ (23.3\%). Bipolar mood disorder, epilepsy, substance-induced disorder and mental retardation were the other most common diagnoses, each representing less than $5 \%$ of the study population.

When comparing the main offences, namely murder, assault, sexual crimes and theft, schizophrenia was found to be the most common psychiatric condition, ranging from a rate of $16.2 \%$ 
among murder offenders to $36.9 \%$ among those charged with theft. In cases of sexual crime and assault the percentages were $26.0 \%$ and $29.7 \%$. The prevalence of schizophrenia was significantly lower among those charged with murder than among those charged with sexual crimes and assault (chi-squared p-values 0.0237 and 0.0267 respectively).

Nearly half the offenders (48.6\%) were found to be triable and accountable, whereas $40.3 \%$ were found to be untriable and unaccountable, $4.9 \%$ were found to have diminished accountability, and $3.5 \%$ were found to be unaccountable.

\section{Conclusion and recommendations}

The majority of the offenders were found to be mentally sound, triable and accountable, and were referred back to the courts. This results in high costs for the Department of Health. To reduce the high rate of unnecessary referrals it is recommended that the courts give clear reasons for the referrals according to each section (77 and 78).

The results of the study also highlight the problem of the mentally handicapped person involved in crime. The reason for this finding seems to be the shortage of supervision, care and rehabilitation facilities for the intellectually disabled.

A significant number of the referred offenders were first diagnosed as being mentally ill only after the crime was committed. One of the reasons might be the fact that some people with psychiatric disorders are not known to and have not been identified by the mental health system. It is therefore of the utmost importance to implement a comprehensive psychiatric community service.
The most worrying finding of the study is the role of alcohol and cannabis in crime. Serious attention must be given to the management and correction of this situation.

The authors thank the management and staff of the Free State Psychiatric Complex, and Cornel van Rooyen of the Department of Biostatistics.

\section{References}

1. Van Rensburg PHIJ. 'n Retrospektiewe studie oor observasie pasiënte gedurende ' $n$ tweejaar periode met ondersoek na die verband tussen die tipe misdaad, die siektediagnose en die ras van die pasiënt. Masters thesis, University of the Free State 1979.
diagnose

2. Hiemstra VG. Suid Afrikaanse Strafproses. 5th ed. Durban: Butterworths, 1993.

3. Tiihonen J, Eronen M, Hakola P. Criminality associated with mental disorders and intellectual deficiency. Arch Gen Psychiatry 1993; 50: $917-918$

4. Verster I, Van Rensburg PHIJ. Mental disorders in patients referred for psychiatric observation after committing homicide. Journal for Jurdical Science 1999; 24(1): 58-66.

5. Vielma M, Vincente B, Hayes GD, Larkin FP, Jenner FA. Mentally abnormal homicide - a review of a special hospital male population. Med Sci Law 1993; 33(1): 47-54.

6. Hansen PE, Schmidt JE. Psychiatric observations 1986 - 1993. Sygehus, Middelfort, the unit of forensic psychiatry. Ugeskr Laeger 1999; 161: 1770-1774.

7. Walker N, McCabe S. Crime and insanity in England. Vol 2. New Solutions and New Problems. Edinburg: University Press, 1973

8. Slabber M, Van Rensburg PHIJ, Gagiano CA, Joubert G, Van Dyk A. The relationship between MRI brain abnormalities and psychiatric disorders. Geneeskunde 1996; 38: Mei/June, 6-12

9. Gagiano CA, Van Rensburg PHJ, Verschoor T. Unnecessary committals for forensic observation: Sections 77 and 78 of the Criminal Procedures Act 51 of 1977. South African Law Journal 1991; 108(1): 714-718

10. Pretorius PJ, Van Rensburg PHIJ, Gagiano CA, Oosthuizen H. Daggagebruik deu wetsoortreders wat deur die hof vir 30 dae psigiatriese observasie verwys word. Geneeskunde 1996; Maart/April, 43-50.

11. Calitz FJW. Die identifisering van kriteria vir verhoorbaarheid. DPhil thesis, University of the Free State, 1990.

12. Cohrane RE, Grisso T, Frederick RT. The relationship between criminal charges, diagnoses and psychological opinions among federal pretrial defendants. Behav SCi Law 2001; 19: 566-582.

13. Roesch R, Golding SL. Competency to Stand Trial. Urbana: University of Illinois Press, 1980.

14. Janet T, Warren JI, Fitch WL, Dietz PE, Rosenfeld BD. Criminal offences, psychiatric diagnosis and psychological opinion. An analysis of 894 pre-trial referrals. Bulletin of the American Academy of Psychiatry and the Law 1991; 19: 63-69.

15. Gold LH. Discovery of mental illness and mental defect among offenders. J Forensic Sci 1973; 18: 125-129. 